\title{
BMJ Open The use and impact of cancer medicines in routine clinical care: methods and observations in a cohort of elderly Australians
}

\author{
Sallie-Anne Pearson, ${ }^{1,2,3}$ Andrea Schaffer ${ }^{1,3}$
}

To cite: Pearson S-A, Schaffer A. The use and impact of cancer medicines in routine clinical care: methods and observations in a cohort of elderly Australians. BMJ Open 2014:4:e004099. doi:10.1136/bmjopen-2013004099

- Prepublication history for this paper is available online. To view these files please visit the journal online (http://dx.doi.org/10.1136/ bmjopen-2013-004099)

Received 23 September 2013 Revised 9 April 2014 Accepted 11 April 2014

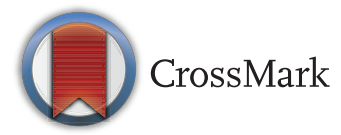

${ }^{1}$ Faculty of Pharmacy, University of Sydney, Sydney, New South Wales, Australia ${ }^{2}$ School of Public Health, Sydney Medical School, University of Sydney, Sydney, New South Wales, Australia ${ }^{3}$ Faculty of Medicine, University of New South Wales, Sydney, New South Wales, Australia

Correspondence to Dr Sallie-Anne Pearson; sallie.pearson@sydney.edu.au

\section{ABSTRACT}

Introduction: After medicines have been subsidised in Australia we know little about their use in routine clinical practice, impact on resource utilisation, effectiveness or safety. Routinely collected administrative health data are available to address these issues in large population-based

pharmacoepidemiological studies. By bringing together cross-jurisdictional data collections that link drug exposure to real-world outcomes, this research programme aims to evaluate the use and impact of cancer medicines in a subset of elderly Australians in the real-world clinical setting.

Methods and analysis: This ongoing research programme involves a series of retrospective cohort studies of Australian Government Department of Veterans' Affairs (DVA) clients. The study population includes 104635 veterans who reside in New South Wales, Australia, and were aged 65 years and over as of 1 July 2004. We will investigate trends in cancer medicines use according to cancer type and other sociodemographic characteristics as well as predictors of the initiation of cancer medicines and other treatment modalities, survival and adverse outcomes among patients with cancer. The programme is underpinned by the linkage of eight health administrative databases under the custodianship of the DVA and the New South Wales Ministry of Health, including cancer notifications, medicines dispensing data, hospitalisation data and health services data. The cancer notifications database is available from 1994 with all other databases available from 2005 onwards.

Ethics and dissemination: Ethics approval has been granted by the DVA and New South Wales Population and Health Service Research Ethics Committees.

Results: Results will be reported in peer-reviewed publications, conference presentations and policy forums. The programme has high translational potential, providing invaluable evidence about cancer medicines in an elderly population who are underrepresented in clinical trials.

\section{INTRODUCTION}

The emergence of effective cancer medicines is acclaimed as one of the major medical advances of the 20th century. ${ }^{1}$ For some cancers, cytotoxic chemotherapy is curative, even in the setting of metastatic disease, and the promise of long-term survival makes the risk of adverse events and financial costs worthwhile. ${ }^{2}$ Adjuvant chemotherapy for breast, colorectal or lung cancer offers significant survival gains beyond surgery alone. For patients with incurable disease, chemotherapy can also lengthen survival. The prospects for patients with cancer have improved further by the recent development of molecular profiling of tumour cells. This technology has facilitated the identification of 'novel, druggable targets' that can be modulated to control or cure cancer. ${ }^{3}$ Moreover, 'personalised medicine' has the potential to optimise treatment efficacy and minimise the toxicity of therapeutic agents. ${ }^{3}$

Drug regulatory bodies and funding agencies play an important role in translating current evidence into policy and clinical practice. Data generated in clinical trials form the basis for regulatory approval because licensing organisations such as the US Food and Drug Administration (FDA) and Australia's Therapeutic Goods Administration (TGA) request that manufacturers demonstrate new medicines are safe and efficacious before approval for marketing. After market approval, governments and other third party payers have developed subsidy systems to achieve greater access to pharmaceuticals. These systems involve a delicate balance between providing access to effective treatments while ensuring long-term fiscal sustainability. ${ }^{4}$ Worldwide, many third party payers now require that healthcare technology manufacturers provide evidence of a product's cost-effectiveness, based mostly on clinical trial evidence, to support subsidy applications.

However, regulatory approval and subsidy decisions are based on the assumption that 
clinical trial outcomes can be extrapolated to the general population. While clinical trials are the indisputable gold standard for demonstrating drug safety and efficacy, they have significant limitations as an evidence base for regulatory and subsidy decisions. ${ }^{5}{ }^{6}$ Some of these drawbacks include: small sample size, short duration, use of surrogate endpoints, early stopping rules that permit cross-over to experimental therapy, lack of measurement of real clinical effects, bias towards younger patients and under-representation of patients with complex health problems. ${ }^{7}$

To add to these well-established limitations, the uncertainties for decision-makers have increased due to stakeholder demand for faster access to potentially life-saving medicines. While fast-track initiatives show commendable responsiveness to stakeholder concerns, the end result is that the premarket approval evidence base is becoming increasingly limited and medicines are reaching the marketplace earlier than ever before. Clearly, no clinical trial could ever be large enough or long enough to quantify all clinical outcomes, risks or otherwise; however, the current situation has created an urgent need to better understand how cancer medicines are prescribed in routine clinical care.

Australians receive subsidised access to a broad range of cancer therapies, including conventional cytotoxics as well as the newer biological agents. Australia is unusual among developed countries as it operates under a National Medicines Policy and a Quality Use of Medicines (QUM) framework. ${ }^{8}$ We have comprehensive policies guiding the production, licensing, subsidy and use of medicines. A significant feature of our QUM framework is the internationally recognised cost-effectiveness analysis model, employed by the Pharmaceutical Benefits Advisory Committee (PBAC) and the Repatriation Pharmaceutical Reference Committee to make recommendations for medicines subsidy on the Pharmaceutical Benefits and Repatriation Pharmaceutical Benefits Schemes (PBS and RPBS), respectively.

After medicines have been subsidised for use in Australia we know little about the way in which they are used in clinical practice, their impact on resource utilisation and whether the people who will derive the most benefit from their use are gaining access to them. This situation persists despite the existence of good quality, routinely collected administrative health data. Australia is in a unique position to undertake population-based pharmacoepidemiological research due to its universal healthcare arrangement and drug coverage for all Australians.

However, health data linkage initiatives have been impeded by privacy concerns and legislation. Moreover, there have been a range of cross-jurisdictional barriers to linking dispensing data (under the custodianship of the Commonwealth) and outcomes data such as hospitalisations (under the custodianship of individual states and territories). Some of the major barriers include the variation in privacy legislation across jurisdictions, lack of transparency and variability about the requirements of jurisdictional ethics committees and the different data release policies of data custodians.

To demonstrate the consequences of this situation we have been undertaking a comprehensive review of all peer-reviewed literature of pharmacoepidemiological research undertaken in Australia using PBS or RPBS dispensing data over a 25-year period (1987-2012). We identified 196 studies, 110 of which were published between 2007 and 2012. Approximately one-third of all published studies $(n=70)$ were based on aggregated claims level data reporting the volume of medicines dispensed over designated time periods. These studies provide little evidence on the way in which medicines are prescribed and used in the Australian population. Another third of all studies $(n=91)$ examined clinician or patient behaviour around a particular medication (coprescribing, potential drug interactions, switching behaviours or patient adherence to therapy). Only 13\% of studies linked individual-level medicines use to a health outcome. Moreover, there have only been six studies with a cancer medicines focus. ${ }^{9-14}$ As such, pharmacoepidemiological research has no systematic framework for undertaking timely studies of medicines use and health outcomes in real-world settings. In direct contrast, the Nordic countries have had long-standing and robust approaches to accessing routinely collected data for pharmacoepidemiological research. In a recent publication, they showcased their pharmacoepidemiological research with an output of 515 research papers in a period of only 6 years $(2005-2010){ }^{15}$

There has been a notable exception in terms of advancing pharmacoepidemiological research in Australia. The Australian Government Department of Veterans' Affairs (DVA) subsidises healthcare and pharmaceuticals for eligible veterans and their dependants, with the collected health claims data available for use in pharmacoepidemiological research. ${ }^{16-27}$ Since the DVA are responsible for all aspects of hospital and community care for their clients they have both exposure and outcomes data under their custodianship. More than one-third of all studies included in our review above used RPBS data. Moreover, more than two-thirds of all studies examining individual level medicines use in our review used RPBS data. To date, the vast majority of the DVA's pharmacoepidemiological research has been conducted under the auspices of the Veterans' Medicines Advice and Therapeutics Education Services (Veterans' MATES) program. ${ }^{28}$ However, cancer pharmacoepidemiology has not been a focus of the Veterans' MATES program.

The programme of work outlined in this protocol brings together cross-jurisdictional data collections to link medicines exposure to real-world outcomes for a subset of elderly Australians residing in New South Wales (NSW), Australia's most populous state. The overall objective of the research programme is to evaluate the use and impact of cancer medicines in the real- 
world clinical setting. Specifically, we will investigate the trends in utilisation of chemotherapeutic and biological agents by cancer type, patterns of care following cancer diagnoses and outcomes associated with cancer medicines use.

\section{METHODS AND ANALYSIS Setting}

Australia has a publicly funded universal healthcare system entitling all Australian citizens and permanent residents to a range of subsidised health services. This includes free treatment in public hospitals (funded jointly by the Commonwealth and State/Territory governments) and subsidised treatment in private hospitals (funded jointly by the Commonwealth and private health insurance). It also includes a range of subsidised outpatient services including consultations with clinicians (funded by the Commonwealth's Medicare Benefits Scheme, MBS) and medicines prescribed in hospitals and in the community (funded by the Commonwealth's PBS; medicines prescribed to public hospital inpatients are covered primarily by the hospital budget).

The DVA funds the healthcare of eligible veterans, war widows, war widowers and their dependants. ${ }^{29}$ In addition to the coverage received by the general population via the MBS and PBS, Repatriation Gold Card holders (ex-prisoners of war, World War I and II veterans and mariners, and their war widows/widowers) are also entitled to additional DVA-approved services and pharmaceutical items not available to the general population. White Card holders (other veterans or mariners who do not qualify for a Gold Card) are entitled to treatment for specific conditions approved by the DVA including a war-related or service-related injury, any malignant cancer and/or tuberculosis. All other conditions are treated and subsidised based on the same entitlements as the Australian general population. The Orange Card provides eligible veterans and mariners of British Commonwealth and allied countries who are 70 years of age or older and Australian residents subsidised access to approved pharmaceuticals according to clinical need. ${ }^{30}$ Clients can hold both White and Orange cards simultaneously.

DVA clients are a major subgroup of the Australian population. In December 2010, they constituted approximately $6 \%$ of Australians aged 65 years and older and $27 \%$ of Australians aged at least 85 years. ${ }^{31}$ Our research programme is limited to all DVA clients residing in the largest Australian state (NSW). DVA clients residing in NSW account for approximately one-third of the Australian DVA population and have a similar and gender profile to clients residing in other Australian states. $^{31}$

\section{Study design}

This ongoing research programme comprises a series of retrospective cohort studies of DVA clients diagnosed with specific cancers. It involves the linkage of eight health administrative databases under the custodianship of the DVA and the NSW Ministry of Health (table 1). Data linkages of this kind have not occurred routinely in other research programmes using DVA claims data.

\section{Data sources}

The linked databases are described below and in table 1 .

\section{DVA client database}

The DVA provide data on clients' sex, dates of birth and death, level of healthcare entitlement history (Gold, White, Orange) and postcode of residence history mapped to statistical local areas (SLAs) and local government areas (LGAs) ${ }^{32}$ The SLAs and LGAs form part of the Australian Standard Geographical Classification, ${ }^{33}$

Table 1 Description of linked data sets

\begin{tabular}{|c|c|c|}
\hline Data set & Description & $\begin{array}{l}\text { Dates available for } \\
\text { current data holdings }\end{array}$ \\
\hline \multicolumn{3}{|c|}{ Department of Veterans' Affairs (DVA) data collections } \\
\hline Client file & Demographics and level of benefits for all DVA clients & 2004-2012 \\
\hline $\begin{array}{l}\text { Repatriation Pharmaceutical } \\
\text { Benefits Scheme }\end{array}$ & $\begin{array}{l}\text { Pharmaceutical items paid for by the DVA dispensed anywhere } \\
\text { in Australia }\end{array}$ & 2004-2012 \\
\hline DVA health services & $\begin{array}{l}\text { All medical and allied health services in the Australian Medicare } \\
\text { Benefits Schedule and extra items paid for by the DVA }\end{array}$ & 2004-2012 \\
\hline Hospital episodes & All hospital episodes in public and private hospitals in Australia & 2005-2012 \\
\hline \multicolumn{3}{|c|}{ New South Wales (NSW) data collections } \\
\hline Central Cancer Registry & All notifications of cancers diagnosed in NSW & 1994-2009 \\
\hline $\begin{array}{l}\text { Register of Births, Deaths } \\
\text { and Marriages }\end{array}$ & All deaths that occurred in NSW & 1994-2012 \\
\hline $\begin{array}{l}\text { Admitted Patients Data } \\
\text { Collection }\end{array}$ & $\begin{array}{l}\text { All inpatient separations from public and private hospitals in } \\
\text { NSW }\end{array}$ & 2000-2012 \\
\hline $\begin{array}{l}\text { Emergency Department } \\
\text { Data Collection }\end{array}$ & $\begin{array}{l}\text { All emergency department visits to a subset of public hospitals } \\
\text { in NSW }\end{array}$ & 2005-2012 \\
\hline
\end{tabular}


established to enable the development of geographyspecific statistics and classification of areas according to socioeconomic profile and remoteness. We did not obtain individual-level data on the service history of the clients in our cohort; however, almost all male DVA clients are veterans of the Australian forces and almost all female clients are war widows. ${ }^{31}$

\section{PBS and RPBS}

The PBS is a national programme subsidising prescription medicines for all Australians, while the RPBS subsidises additional items for DVA clients. It contains data on all dispensed pharmaceutical items (item name and strength, date of supply, quantity supplied and number of repeats) that were subsidised in whole or in part by the DVA and dispensed in the community or in a private hospital anywhere in Australia.

\section{DVA hospital episodes}

The DVA collects information on all hospitalisations to public and private hospitals across Australia where the hospital stay was subsidised by the DVA, including dates of stay, primary diagnosis and primary procedure. Claims from public and private hospitals are processed differently and there is a significant lag in the capture of public hospital claims (up to 1 year from the date of service in some instances).

\section{DVA health services}

These data contain all billed medical and allied health services performed anywhere in Australia both in-hospital and out-of-hospital that are covered under Australia's national MBS, as well as additional items covered by the DVA. MBS items include physician visits, diagnostic and therapeutic procedures and pathology tests and additional DVA items including services provided by dentists, podiatrists, chiropractors and dieticians.

\section{NSW Central Cancer Registry}

The Central Cancer Registry (CCR) records all cancer cases diagnosed in NSW residents. The registry is run according to the International Association of Cancer Registries' rules $^{34}$ and records the cancer type (ICD-O-3), date of diagnosis, degree of spread at the time of first diagnosis for solid tumours and the date and cause of death (cancer or non-cancer). ${ }^{35}$

\section{NSW Admitted Patients Data Collection}

The Admitted Patients Data Collection (APDC) is a census of all inpatient separations (ie, discharges, transfers, deaths) from all public, private and repatriation hospitals, private day procedures centres and public nursing homes in NSW and collects data on the dates of admission and separation, and up to 50 diagnoses and procedures.
Emergency Department Data Collection

The Emergency Department Data Collection (EDDC) records the date, the reason for the visit and the visit outcome (eg, admission to hospital, death or discharge) for all ED visits to 90 public EDs across NSW. There are 150 EDs in NSW, two of which are located in private hospitals. All of the larger EDs contribute data to the EDDC so the data set includes the majority of ED attendances. ${ }^{36}$ Moreover, using the APDC, it is possible to identify ED presentations which resulted in an admission to hospital.

NSW Register of Births, Deaths and Marriages (RBDM) plus Australian Bureau of Statistics Cause of Death

The RBDM records all births and deaths in NSW. Details of all registered deaths are forwarded to the ABS where causes of death codes (ICD-10) are applied to each record. The coded data then form part of the registered death information. However, there is often a significant lag between fact and cause of death data due to the time taken to process cause of death information.

\section{Data linkage}

The first linked data were obtained in 2011. The data linkage was performed by the Centre for Health Record Linkage (CHeReL) which maintains a record linkage system for health-related data in NSW and the Australian Capital Territory in accordance with all ethical, legal, privacy and confidentiality requirements. The CHeReL keeps a Master Linkage Key that consists of continuously updated links between most NSW data sets.

The DVA provided the CHeReL with an encrypted client number and personal information for all clients. The CHeReL then assigned a project person number (PPN) to each DVA client. A 'project key' containing the PPN and encrypted client number for each respective database is sent to the various data custodians who decrypted the client number and attached the PPNs and requested content variables. These were subsequently sent to the researchers stripped of personally identifying information such as name and address. All the data sets were joined by the researchers using the PPNs. This process is outlined in figure 1.

The linkage used probabilistic matching ${ }^{37}$ using the record linkage software ChoiceMaker, ${ }^{38}$ together with clerical review of possible matches. Probabilistic matching assigns a weight to pairs of records based on how likely they are to be a true match based on a comparison of name, date of birth and address. Records with high weights are considered a true match while those with low weights are false matches; uncertain matches undergo clerical review. The cut-off for determining whether a match is true or false is chosen as to minimise the number of false positives, false negatives and the number of clerical reviews. ${ }^{39}$ The linkage algorithms take into account name reversals, name shortenings and a limited number of keystroke errors in date of birth. The CHeReL routinely performs these linkages, and 


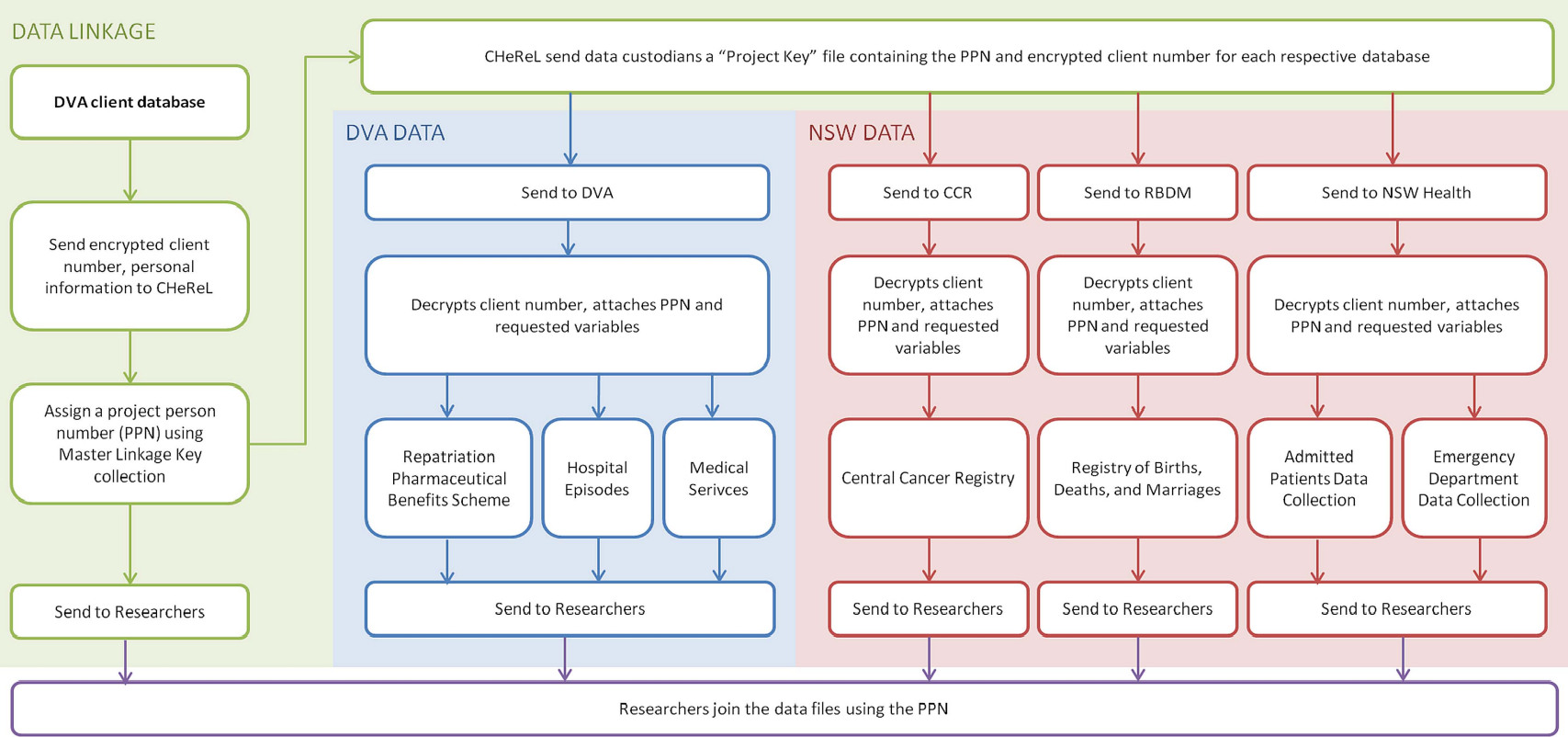

Figure 1 Data linkage process. CHeReL, Centre for Health Record Linkage; DVA, Department of Veterans' Affairs; NSW, New South Wales.

standard operating procedures exist to fine tune the linkage sensitivity and specificity depending on the cohort data being linked. CHeReL follows established quality assurance processes for their master linkage key, linkage procedures and linkage staff. In general, these processes achieve false positive rates of $0-5 / 1000$ and false negative rates of $<1 / 1000$. However, the quality of the probabilistic matching process is highly dependent on the quality of the data provided, and in the case of DVA clients, important linkage variables such as name, date of birth and death and address histories are well documented. For example, an audit of the first CCR, APDC and EDDC linkages found a false positive rate of $0.4 \%$ and a false negative rate of $<0.5 \%$. Moreover, individual research projects conducted under the auspices of this programme start with a comprehensive review of the cohort to minimise the inclusion of false positive cases. This is carried out by identifying and excluding cases where there are discrepancies between dates of birth and death across different databases or in circumstances where a client has observations of health resource use after their date of death.

\section{Study population}

As this is an ongoing study, the characteristics of the population change over time. Characteristics of the study population as described below are summarised for each client at 1 July 2004 or the date of their first healthcare entitlement, whichever occurred later. There were 104635 DVA clients who resided in NSW, were aged 65 years or older and received full or partial funding of medicines and/or health services. Figure 2 shows the proportion of the NSW population represented by DVA clients.
The vast majority of these DVA clients $(89 \%)$ received full healthcare entitlements (Gold Card holders). For these individuals there will be almost complete ascertainment of subsidised healthcare utilisation by combining DVA and NSW databases; it is this subpopulation that we will generally use for analysis of health services utilisation and medicines use. An additional 5\% received subsidised pharmaceuticals only (Orange Card holders). Inclusion of this cohort in analyses would be appropriate to answer research questions that require pharmaceutical claims data only. Finally, $6 \%$ of DVA clients received subsidies for health services and pharmaceuticals related to the treatment of specific conditions related to service or any malignancy (White Card holders). Inclusion of this cohort would be appropriate for research questions about the medicines and health service use of clients with cancer.

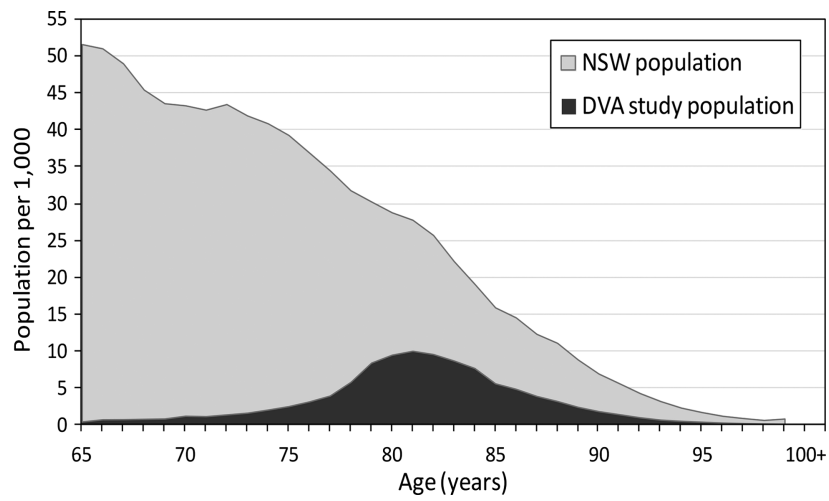

Figure 2 Age distribution of New South Wales population and Department of Veterans' Affairs population, July 2004. 
Over half (52\%) of Gold Card holders were women, while men were the vast majority of White and Orange Card holders (table 2). The gender disparity at different levels of entitlement reflects the fact that the majority of female DVA clients are war widows, ${ }^{31}$ who are not eligible for White or Orange Cards. Most clients were aged between 80 and 84 years. Given the older age of this population, attrition was high with approximately $7 \%$ dying every year of follow-up. A quarter of clients (26\%) had been diagnosed with cancer, with prostate, skin and colorectal cancers being the most common. White and Orange Card holders were less likely to have breast cancer given the fewer number of women with these entitlements. In a 1-year period, $54 \%$ of all DVA clients had no hospitalisations. Among those hospitalised, the comorbidity burden as measured by the Charlson index ${ }^{40}$ was low, with most having an index of 0 (table 2). Since the collection of hospital separation data is provided by the NSW Ministry of Health, it is not dependent on DVA subsidy, so there was little variation by level of DVA healthcare entitlement. In contrast, given the limited subsidy of pharmaceutical items among White Card holders, this group was more likely to have had no dispensing records in a 1-year period. When comorbidities are defined using the RxRisk, ${ }^{41}$ approximately one quarter of clients had seven or more comorbidities (table 2). Nearly two-thirds of clients lived in major cities (defined by the Accessibility/Remoteness Index of Australia),${ }^{42}$ and nearly one-third resided in areas classified as the least disadvantaged (defined by the Index of Relative Socio-Economic Disadvantage ${ }^{43}$; table 2).

Statins were the most common class of medicines dispensed, representing between $7 \%$ and $8 \%$ of all dispensing records in a 1-year period, followed closely by proton pump inhibitors (6-7\%; table 3). Among Gold Card holders, $43 \%$ of patients were ever dispensed paracetamol and $37 \%$ were ever dispensed a statin over a 1-year period. Among White and Orange Card holders, 19\% and $34 \%$, respectively, were ever dispensed a statin (table 3). The lower percentage among White Card holders likely reflects their lower rate of subsidy for pharmaceuticals. Cancer medicine use, including chemotherapy and hormone therapy, represented only $0.5 \%$ of dispensing records. Over a 1-year period the most commonly dispensed antineoplastics were gonadotropin-releasing hormone analogues, such as goserelin, and pyrimidine analogues, such as capecitabine, reflecting the high rates of prostate and colorectal cancers (table 4 ).

DVA clients were high users of health services, with 64 health services per person-year. The majority of these were consultations and visits with healthcare professionals $(41 \%)$, followed by pathology services $(25 \%)$ and diagnostic and therapeutic procedures (14\%; table 5).

\section{Statistical analysis}

We will use a range of pharmacoepidemiological analyses to explore cancer medicines use and outcomes across our programme of work. We will identify patients diagnosed with cancer using cancer registry data, while we will identify users of cancer medicines based on pharmaceutical dispensing data. When determining specific research questions we will account for the availability and quality of the various data sources, the presence of secular trends and geographical variation that may affect the outcomes of the study. Importantly, the most contemporary cancer notification data are only available to Australian researchers until 2009, but outcomes that result in hospitalisation can be ascertained up until 2012. The predominant approaches are outlined below.

\section{Cancer medicines use}

We will ascertain use of cancer medicines using the pharmaceutical dispensing data. We will map all medicines to their WHO Anatomical Therapeutic Chemical (ATC) classification; medicines in the ATC categories L01 ('antineoplastic agents') and L02 ('endocrine therapy') will be the primary medicines of interest. Since the dispensing data do not contain information on the daily dose, we will develop an algorithm for each medicine of interest based on the amount dispensed, the number of repeats, the average time between refills by person and typical dosage, as we have carried out previously. ${ }^{10-12}$ Where this is not practicable we will use the WHO's 'defined daily dose'. Using the hospital episode data we will also identify the administration of antineoplastic agents to public hospital inpatients, as medicines dispensed to these patients do not appear in the dispensing data.

\section{Patterns of use}

We will examine the trends in cancer medicines use using the following measures: cumulative incidence by medicine type over time, prevalence of use by medicine type by age group and by year, duration of use, average daily dose and the concomitant use of multiple cancer medicines. We will also estimate 'off-label' use of cancer medicines by using information about concomitant use of specific cancer medicines. We will report the characteristics of patients dispensed cancer medicines, specifically age, sex, geographical remoteness and area of socieconomic disadvantage, cancer type, disease spread and presence of comorbidities, and whether this changes over time. Age, sex, geographical remoteness and area of socieconomic disadvantage will be ascertained from the DVA client database, while cancer type and spread is available from the cancer registry. We will identify comorbidities using the Charlson index, ${ }^{44}$ and/ or the Elixhauser index ${ }^{45}$; both indexes use diagnosis information from hospital separation data to identify comorbidities, and therefore clients who are not hospitalised will not be captured by these indices. Therefore, the RxRisk ${ }^{41}$ will also be used; this index uses dispensed medicines to identify 41 comorbidities. 
Table 2 Demographics of those alive, living in New South Wales and $\geq 65$ years of age at 1 July 2004 or date of first healthcare entitlement

\begin{tabular}{|c|c|c|c|c|c|c|c|c|}
\hline & \multicolumn{6}{|c|}{ Department of Veterans' Affairs healthcare entitlement level } & \multirow[b]{2}{*}{$\begin{array}{l}\text { Total } \\
\text { n (\%) }\end{array}$} & \\
\hline & $\begin{array}{l}\text { Gold } \\
\text { n (\%) }\end{array}$ & & $\begin{array}{l}\text { White } \\
\text { n (\%) }\end{array}$ & & $\begin{array}{l}\text { Orang } \\
\text { n (\%) }\end{array}$ & & & \\
\hline \multicolumn{9}{|l|}{ Sex } \\
\hline Male & 44480 & $(47.6)$ & 5921 & (83.8) & 4928 & $(98.0)$ & 54508 & (52.1) \\
\hline Female & 48890 & (52.4) & 1143 & (16.2) & 100 & $(2.0)$ & 50127 & (47.9) \\
\hline \multicolumn{9}{|l|}{ Age in years } \\
\hline $65-74$ & 9363 & (10.0) & 855 & (12.1) & 18 & $(0.4)$ & 10230 & (9.8) \\
\hline $75-79$ & 20632 & (22.1) & 1972 & (27.9) & 1104 & (22.0) & 23539 & (22.5) \\
\hline 80-84 & 39983 & (42.8) & 2850 & (40.4) & 2879 & (57.3) & 45234 & (43.2) \\
\hline $85-89$ & 17884 & (19.2) & 1069 & (15.1) & 881 & (17.5) & 19682 & (18.8) \\
\hline $90+$ & 5508 & $(5.9)$ & 318 & $(4.5)$ & 146 & $(2.9)$ & 5950 & $(5.7)$ \\
\hline \multicolumn{9}{|l|}{ Alive at† (year) } \\
\hline 1 & 88781 & $(96.2)$ & 6773 & $(96.6)$ & 4837 & (96.3) & 99600 & (96.3) \\
\hline 2 & 80812 & (89.3) & 6162 & (89.7) & 4440 & (88.6) & 90687 & (89.3) \\
\hline 3 & 73134 & (82.4) & 5353 & (81.8) & 4022 & (80.8) & 81868 & (82.3) \\
\hline 4 & 65286 & (75.1) & 4689 & (75.3) & 3575 & (72.7) & 72985 & (75.1) \\
\hline 5 & 57601 & (67.9) & 4079 & (68.8) & 2802 & (63.8) & 63991 & (67.8) \\
\hline \multicolumn{9}{|l|}{ Cancer diagnosis (since 1994) } \\
\hline Any cancer & 23993 & (25.7) & 2515 & (35.6) & 1396 & $(27.8)$ & 27651 & (26.4) \\
\hline Prostate (C61) & 6122 & $(6.6)$ & 895 & (12.7) & 527 & (10.5) & 7452 & $(7.1)$ \\
\hline Skin (C44) & 5432 & $(5.8)$ & 615 & $(8.7)$ & 165 & (3.3) & 6162 & (5.9) \\
\hline Colorectal (C18-C20) & 4109 & (4.4) & 389 & (5.5) & 203 & $(4.0)$ & 4661 & (4.5) \\
\hline Breast (C50) & 2342 & (2.5) & 137 & (1.9) & 7 & $(0.1)$ & 2485 & (2.4) \\
\hline Bronchus and lung (C34) & 1899 & (2.0) & 179 & (2.5) & 151 & (3.0) & 2204 & (2.1) \\
\hline Other & 8291 & (8.9) & 559 & (7.9) & 850 & (16.9) & 9617 & $(9.2)$ \\
\hline \multicolumn{9}{|l|}{ Charlson index $\ddagger$} \\
\hline 0 & 28746 & $(30.8)$ & 2156 & (30.5) & 1320 & (26.3) & 31970 & (30.6) \\
\hline $1-2$ & 9655 & $(10.3)$ & 743 & (10.5) & 572 & (11.4) & 10876 & (10.4) \\
\hline $3+$ & 4713 & $(5.1)$ & 448 & (6.3) & 328 & $(6.5)$ & 5430 & (5.2) \\
\hline No hospitalisations & 50256 & (53.8) & 3717 & (52.6) & 2808 & (55.9) & 56359 & (53.9) \\
\hline \multicolumn{9}{|l|}{ RxRisk†‡ } \\
\hline $0-2$ comorbidities & 17255 & $(18.7)$ & 1253 & (17.9) & 1018 & (20.3) & 19348 & (18.7) \\
\hline 3-4 comorbidities & 23016 & (25.0) & 1572 & (22.4) & 1208 & (24.0) & 25578 & (24.7) \\
\hline $5-6$ comorbidities & 22151 & (24.0) & 1550 & (22.1) & 1172 & (23.3) & 24657 & (23.8) \\
\hline $7+$ comorbidities & 24230 & (26.3) & 1635 & (23.3) & 1176 & (23.4) & 26841 & (25.9) \\
\hline No dispensing records & 5608 & $(6.1)$ & 1002 & (14.3) & 450 & $(9.0)$ & 7045 & $(6.8)$ \\
\hline \multicolumn{9}{|c|}{ Accessibility/Remoteness Index of Australia category } \\
\hline Major cities of Australia & 57681 & $(61.8)$ & 4378 & $(62.0)$ & 3617 & (71.9) & 65106 & (62.2) \\
\hline Inner regional Australia & 26314 & (28.2) & 2012 & (28.5) & 1147 & (22.8) & 29260 & (28.0) \\
\hline Outer regional Australia & 8324 & $(8.9)$ & 573 & $(8.1)$ & 232 & $(4.6)$ & 9093 & $(8.7)$ \\
\hline Remote/very remote Australia & 470 & $(0.5)$ & 23 & $(0.3)$ & 8 & $(0.1)$ & 499 & $(0.5)$ \\
\hline Unknown & 581 & $(0.6)$ & 78 & (1.1) & 24 & (0.5) & 677 & $(0.7)$ \\
\hline \multicolumn{9}{|c|}{ Index of Relative Socio-Economic Disadvantage } \\
\hline Most disadvantaged & 12647 & $(13.6)$ & 823 & $(11.7)$ & 556 & $(11.1)$ & 13949 & (13.3) \\
\hline Second quintile & 12622 & (13.5) & 1013 & (14.3) & 661 & (13.2) & 14156 & (13.5) \\
\hline Third quintile & 20984 & (22.5) & 1563 & (22.1) & 1175 & (23.4) & 23548 & (22.5) \\
\hline Fourth quintile & 18663 & $(20.0)$ & 1342 & $(19.0)$ & 1057 & $(21.0)$ & 20906 & (20.0) \\
\hline Least disadvantaged & 27873 & (29.9) & 2245 & (31.8) & 1555 & (30.9) & 31399 & (30.0) \\
\hline Unknown & 581 & $(0.6)$ & 78 & (1.1) & 24 & $(0.5)$ & 677 & $(0.7)$ \\
\hline Total & 93370 & $(100.00)$ & 7064 & $(100.0)$ & 5028 & $(100.0)$ & 104635 & $(100.0)$ \\
\hline
\end{tabular}

Patterns of care

After identifying patients with cancer, we will describe the treatment pathway for specific cancer types after diagnosis. We will identify the receipt of cancer-related surgery, radiation therapy and chemotherapy using: (1) hospital separation data to identify in-hospital surgery, 
Table 3 Most common Repatriation Pharmaceutical Benefits Scheme medicines dispensed in a 1-year period

\begin{tabular}{|c|c|c|c|c|}
\hline \multirow[b]{2}{*}{ Drug category } & \multirow[b]{2}{*}{ Examples } & \multicolumn{3}{|c|}{$\begin{array}{l}\text { Level of Department of Veterans' Affairs } \\
\text { entitlement }\end{array}$} \\
\hline & & $\begin{array}{l}\text { Gold } \\
\text { n (\%) }\end{array}$ & $\begin{array}{l}\text { White } \\
\text { n (\%) }\end{array}$ & $\begin{array}{l}\text { Orange } \\
\mathrm{n}(\%)\end{array}$ \\
\hline \multicolumn{5}{|l|}{ By number of dispensing records } \\
\hline $\begin{array}{l}\text { HMG-coenzymeA reductase } \\
\text { inhibitors (C10AA) }\end{array}$ & Atorvastatin, simvastatin & $326897(6.8)$ & $10007(7.2)$ & $14551(8.2)$ \\
\hline Proton pump inhibitors (A02BC) & Omeprazole, pantoprazole & $295844(6.1)$ & $9146(6.5)$ & $10385(5.9)$ \\
\hline ACE inhibitors, plain (CO9AA) & Perindopril, ramipril & $234476(4.8)$ & $7275(5.2)$ & $10722(6.1)$ \\
\hline Anilides (N02BE) & Paracetamol & 187639 (3.9) & $4723(3.4)$ & $5691(3.2)$ \\
\hline $\begin{array}{l}\text { Platelet aggregation inhibitors } \\
\text { excluding heparin (B01AC) }\end{array}$ & Clopidogrel, aspirin & $173264(3.6)$ & $5070(3.6)$ & $6256(3.5)$ \\
\hline Dihydropyridine derivatives (C08CA) & Amlodipine, nifedipine & 142419 (2.9) & $4044(2.9)$ & $5955(3.4)$ \\
\hline $\begin{array}{l}\text { Angiotensin II antagonists, plain } \\
\text { (C09CA) }\end{array}$ & Irbesartan, candesartan & $130240(2.7)$ & $3809(2.7)$ & $4655(2.6)$ \\
\hline Organic nitrates (C01DA) & $\begin{array}{l}\text { Isosorbide mononitrate, } \\
\text { glyceryl trinitrate }\end{array}$ & $114774(2.4)$ & $3480(2.5)$ & $5205(3.0)$ \\
\hline$\beta$-Blocking agents, selective (C07AB) & Atenolol, metoprolol & $114395(2.4)$ & $3253(2.3)$ & $4373(2.5)$ \\
\hline Benzodiazepine derivatives (N05CD) & Temazepam, nitrazepam & $114964(2.4)$ & $3230(2.3)$ & $3880(2.2)$ \\
\hline Total number of dispensing records & & $5025507(100.0)$ & $144644(100.0)$ & $181444(100.0)$ \\
\hline \multicolumn{5}{|c|}{ By number of people with $\geq 1$ dispensing record } \\
\hline Anilides (N02BE) & Paracetamol & $39766(43.1)$ & $1238(17.7)$ & $1443(28.7)$ \\
\hline $\begin{array}{l}\text { HMG-coenzymeA reductase } \\
\text { inhibitors }(\mathrm{C} 10 \mathrm{AA})\end{array}$ & Atorvastatin, simvastatin & $34382(37.3)$ & $1344(19.2)$ & $1702(33.9)$ \\
\hline Proton pump inhibitors (A02BC) & Omeprazole, pantoprazole & 33905 (36.7) & $1322(18.9)$ & $1369(27.2)$ \\
\hline $\begin{array}{l}\text { Platelet aggregation inhibitors } \\
\text { excluding heparin (B01AC) }\end{array}$ & Clopidogrel, aspirin & 32526 (35.3) & $1092(15.6)$ & $1283(25.5)$ \\
\hline $\begin{array}{l}\text { First-generation cephalosporins } \\
\text { (J01DB) }\end{array}$ & Cephalexin, cephalotin & 26707 (28.9) & $896(12.8)$ & $911(18.1)$ \\
\hline ACE inhibitors, plain (C09AA) & Perindopril, ramipril & 25985 (28.2) & $998(14.2)$ & $1305(26.0)$ \\
\hline Other opthalmologicals (S01XA) & Eye drops & $20666(22.4)$ & $574(8.2)$ & $566(11.3)$ \\
\hline Sulfonamides, plain (C03CA) & Frusemide, bumetanide & $18850(20.4)$ & $590(8.4)$ & $780(15.5)$ \\
\hline Benzodiazepine derivatives (N05CD) & Temazepam, nitrazepam & $18798(20.4)$ & $673(9.6)$ & $719(14.3)$ \\
\hline $\begin{array}{l}\text { Corticosteroids, potent (group III) } \\
\text { (D07AC) }\end{array}$ & $\beta$-Methasone, mometasone & $18566(20.1)$ & $674(9.6)$ & 768 (15.3) \\
\hline \multicolumn{2}{|c|}{ Total number of people with 1 year of dispensing data } & $92260(100.0)$ & $7012(100.0)$ & $5024(100.0)$ \\
\hline
\end{tabular}

radiation therapy and chemotherapy; (2) pharmaceutical dispensing data to identify the dispensing of antineoplastic medicines in-hospital and out-of-hospital and (3) health services data to identify in-hospital and out-of-hospital surgery, radiation therapy and chemotherapy. We will further examine the temporal relationship between date of diagnosis and the receipt of different treatment types; where treatment is identified from multiple data sources, we will compare dates to avoid double counting.

In addition, where relevant, we will ascertain that appropriate monitoring is being performed for known side effects of cancer medicines using procedures and tests identified in health services data.

\section{Health services utilisation}

We will quantify the use of health services in the period prior to diagnosis. These include: the number of hospital separations and days spent in hospital, identified using the hospital separation data; the number of general practitioner consultations, specialist consultations and allied health consultations, identified using the health services data and the number of ED visits, identified using the ED data.

\section{Predictors of health outcomes}

We will identify predictors of the receipt of any treatment, and type of treatment, using logistic regression models. We will also examine predictors of time to therapy and time to death (both cancer death and allcause mortality) using Kaplan-Meier curves and Cox proportional hazards models. Date of death will be ascertained using the DVA client database, while cause of death (cancer vs non-cancer) is provided by the cancer registry data. We will identify predictors of the rate of health service utilisation using Poisson regression or negative binomial regression, as appropriate. In all models the predictors we will consider include age at diagnosis, sex, geographical remoteness and area of 
Table 4 Most common Repatriation Pharmaceutical Benefits Scheme cancer medicines (ie, cytotoxic and hormone therapy) dispensed in a 1-year period

\begin{tabular}{|c|c|c|c|c|}
\hline \multirow[b]{2}{*}{ Drug category } & \multirow[b]{2}{*}{ Examples } & \multicolumn{3}{|c|}{$\begin{array}{l}\text { Level of Department of Veterans' Affairs } \\
\text { entitlement }\end{array}$} \\
\hline & & $\begin{array}{l}\text { Gold } \\
\text { n (\%) }\end{array}$ & $\begin{array}{l}\text { White } \\
\text { n (\%) }\end{array}$ & $\begin{array}{l}\text { Orange } \\
\mathrm{n}(\%)\end{array}$ \\
\hline \multicolumn{5}{|l|}{ By number of dispensing records } \\
\hline $\begin{array}{l}\text { Gonadotropin-releasing hormone analogues } \\
\text { (L02AE) }\end{array}$ & Leuprorelin, goserelin & $7184(27.3)$ & $723(39.3)$ & $531(44.3)$ \\
\hline Pyrimidine analogues (L01BC) & $\begin{array}{l}\text { Fluorouracil, } \\
\text { capecitabine }\end{array}$ & $3370(12.8)$ & $243(13.2)$ & $73(6.1)$ \\
\hline Antiandrogens (L02BB) & Flutamide, bicalutamide & $2898(11.0)$ & $240(13.0)$ & $217(18.1)$ \\
\hline Antiestrogens (L02BA) & Tamoxifen, toremifene & 3191 (12.1) & $89(4.8)$ & $57(4.8)$ \\
\hline Folic acid analogues (L01BA) & Methotrexate, raltitrexed & $2211(8.4)$ & $57(3.1)$ & $16(1.3)$ \\
\hline Total number of cancer medicine dispensing records & & $26290(100.0)$ & $1840(100.0)$ & $1200(100.0)$ \\
\hline \multicolumn{5}{|l|}{ By number of people with $\geq 1$ dispensing record } \\
\hline Pyrimidine analogues (L01BC) & $\begin{array}{l}\text { Fluorouracil, } \\
\text { capecitabine }\end{array}$ & $2267(2.5)$ & $145(2.1)$ & $49(1.0)$ \\
\hline $\begin{array}{l}\text { Gonadotropin-releasing hormone analogues } \\
\text { (L02AE) }\end{array}$ & Leuprorelin, goserelin & $1854(2.0)$ & $184(2.6)$ & $145(2.9)$ \\
\hline Antiestrogens (L02BA) & Tamoxifen, toremifene & $664(0.7)$ & $24(0.3)$ & $6(0.1)$ \\
\hline Folic acid analogues (L01BA) & Methotrexate, raltitrexed & $641(0.7)$ & $28(0.4)$ & $24(4.8)$ \\
\hline Antiandrogens (L02BB) & Flutamide, bicalutamide & $472(0.5)$ & $41(0.6)$ & $37(0.7)$ \\
\hline \multicolumn{2}{|c|}{ Total number of people with 1 year of dispensing data } & $92260(100.0)$ & $7012(100.0)$ & $5024(100.0)$ \\
\hline
\end{tabular}

socieconomic disadvantage, cancer type, disease spread at diagnosis and comorbidities.

We will also investigate the risk of specific adverse outcomes in clients with cancer who are taking a particular medicine, compared to a similar group of patients naive to the medicine of interest. Adverse outcomes will be identified using information such as: the dispensing of a new medicine that indicates the development of a new disease, a hospital separation with a diagnosis of the outcome of interest a new notified cancer and mortality. Care will be taken when selecting the comparison group to avoid confounding by indication; where practicable, we will apply high-dimensional propensity score analysis ${ }^{46}$ using the following dimensions: dispensed medicines, hospital diagnoses, hospital procedures and physician visit procedures. We will investigate the relationship between the timing of the adverse event and use of the medicine of interest using time-dependent Cox proportional hazard models. ${ }^{47}$ To best describe the relationship between the medicine of interest and the outcome, we will define medicine use in several different ways, using the daily dose information as described above, that is, any use, total cumulative dose, current dose, cumulative dose in the past 30 days, and recent initiation and/or discontinuation. Using different measures of medicine use will also allow us to perform sensitivity analyses to assess the robustness of our results.

Analyses will be performed using SAS Version 9.3, Stata Version 12 and R Version 3.1.0.

\section{Validation and feasibility}

As in any epidemiological study we must consider the potential biases in our research. Some of the concerns raised in relation to administrative database research

Table 5 Number of health service records by type over a 1-year period

\begin{tabular}{lccc} 
& \multicolumn{2}{l}{ Level of Department of Veterans' Affairs entitlement } \\
\cline { 2 - 4 } & Gold & White & Orange \\
$\mathbf{n}(\%)$ & $\mathbf{n}(\%)$ & $160087(40.0)$ & $119923(40.2)$ \\
\hline Attendances/consults/visits & $2380445(40.7)$ & $72918(18.2)$ & $50970(18.3)$ \\
$\quad$ General practitioner & $1092432(18.7)$ & $31967(8.0)$ & $22980(8.3)$ \\
$\quad$ Specialist & $456327(7.8)$ & $102413(25.6)$ & $68656(24.7)$ \\
Pathology services & $1461671(25.0)$ & $58760(14.7)$ & $42597(15.3)$ \\
Procedures & $820958(14.1)$ & $24740(6.2)$ & $18064(6.5)$ \\
$\quad$ Diagnostic & $358825(6.1)$ & $34020(8.5)$ & $24533(8.8)$ \\
$\quad$ Therapeutic & $462133(7.9)$ & $79130(19.8)$ & $55157(19.8)$ \\
Miscellaneous (eg, administrative, medical supplies) & $1181775(20.2)$ & $400390(100.0)$ & $278337(100.0)$ \\
Total number of health services & $5844856(100.0)$ & &
\end{tabular}


and the conduct of pharmacoepidemiological research in Australia are described below.

\section{Medicine exposure}

Electronic pharmacy dispensing records are considered the gold standard of prescribed medicines exposure information, compared with patient notes and selfreported information. ${ }^{48} 49$ In addition, undertaking studies in the DVA client population have the distinct advantages of having good ascertainment of prescribed medicines use, even relatively cheap medicines that are not always captured in the general population. In Australia, we have comprehensive pharmaceutical claims data collections for prescribed medicines dispensed in community and private hospitals, but not for public hospital inpatients. Given the vast majority of oncology protocols are administered in the outpatient setting or to private hospital inpatients (both of which are captured in the $\mathrm{R} / \mathrm{PBS}$ data), we believe this issue will not impact significantly on the outcomes of our analyses. However, if in the unlikely event that chemotherapy is administered to public hospital inpatients, it is indicated as a procedure code in the public hospital separation record. While we will not know the nature of the chemotherapy we can identify an episode when chemotherapy was administered in hospital, allowing us to estimate the chemotherapy use that was not identified in the R/PBS dispensing data. While there are clear limitations in terms of complete ascertainment of cancer medicines dispensing claims, our approach remains the best way of defining medicines exposure in whole of population studies. Since it is highly unlikely that we would miss every administration of a cancer medicine over the course of a chemotherapy protocol, we will almost certainly identify most patients who had received some type of cancer drug treatment.

\section{Diagnosis, outcome and covariate misclassification}

As the health administrative data sets lack detailed clinical information, one needs to assess the impact of misclassifying diagnoses and outcomes of interest. The accuracy of cancer incidence in DVA clients depends on the completeness and accuracy of the NSW CCR. Routine indicators of data quality and completeness show the Australian State and Territory cancer registries are operating in accordance with international standards. ${ }^{50}$ In terms of outcomes of interest, poor sensitivity may be an issue as we commonly identify outcomes that result in hospitalisation before we can identify potential outcomes of interest and the health service records contain no diagnostic information. However, poor specificity of the outcome is worse than a lack of sensitivity in most situations. ${ }^{51}$ If the specificity of the outcome is $100 \%$ then relative risk estimates are unbiased. A recent comprehensive study on the misclassification of claims data diagnoses using medical record chart review as the gold standard revealed the sensitivity of claims diagnoses is often less than moderate whereas specificity is usually
$95 \%$ or greater. A high specificity of diagnostic coding in claims data can be expected because if a diagnosis is coded and recorded it is likely the diagnosis was made. ${ }^{52}$

The data also lack certain important covariates, including health behaviours such as smoking, drinking habits and obesity. Further, our data set is not linked to DVA military service records. In hospital separation data, comorbidities are only recorded if they are directly related to the reason for admission. As a result, there have been several algorithms developed to identify the presence of important comorbidities using administrative claims data, including in hospitalisation data (such as the Charlson index ${ }^{53}$ ) and in dispensing data (such as the RxRisk ${ }^{54}$ ).

In the general population, recording of services provided by Medicare Australia (ie, health services and dispensed medicines) is tied to those subsidised (in part or in full) by the government; therefore the record of their healthcare utilisation is incomplete, limiting the sorts of analyses that can be conducted. In contrast, the utilisation of health services by Australian veterans is nearly totally subsidised by the DVA, meaning there is nearcomplete capture of health services and hospital visits, creating a unique opportunity for study. The availability of data across multiple sources allows for validation of important endpoints such as death, for which we will have date of death information from a minimum of three sources and cause of death from a minimum of two sources (table 6).

\section{Multiple data sources and observations}

One of the greatest strengths of the DVA/NSW data linkage is the multiple data sources for the key analysis variables (table 2). For example, we will use hospital separation data from both NSW and DVA data sets. While some of this information is clearly duplicated, each data set brings its own unique benefits. The NSW APDC will contain hospital separations for DVA clients in NSW, and the DVA hospital episodes will record any hospital separation (as a DVA client) regardless of where it occurred in Australia.

\section{External validity of research findings}

One potential limitation of this research programme is that the health seeking behaviour and health outcomes of the veterans' population may not be representative of older Australians. However, when compared with Australians of similar age, DVA clients have been shown to have very similar rates of health service and medicine use. ${ }^{55}$

\section{Ethics and dissemination}

The work outlined in this protocol describes a programme of research examining the real-world use and impacts of cancer medicines in a population of elderly Australians. The first linkages and data access occurred in 2011 and we have ongoing human research ethics approval until 2015. 
Table 6 Data sources containing key analysis variables

\begin{tabular}{|c|c|c|c|c|c|c|c|c|}
\hline & \multicolumn{4}{|c|}{ Department of Veterans' Affairs } & \multicolumn{4}{|c|}{ New South Wales } \\
\hline & $\begin{array}{l}\text { Client } \\
\text { data }\end{array}$ & RPBS & $\begin{array}{l}\text { Medical } \\
\text { services }\end{array}$ & $\begin{array}{l}\text { Hospital } \\
\text { episodes }\end{array}$ & CCR & APDC & RBDM & EDDC \\
\hline Cancer diagnoses & & & & & $\checkmark$ & $\checkmark$ & & \\
\hline Hospitalisations & & & & $\checkmark$ & & $\checkmark$ & & \\
\hline Prescribed medicines use & & $\checkmark$ & & & & $\boldsymbol{J}^{*}$ & & \\
\hline Health service use & & & $\checkmark$ & & & $\checkmark$ & & \\
\hline $\begin{array}{l}\text { Emergency department } \\
\text { visits }\end{array}$ & & & & & & & & $\checkmark$ \\
\hline Date of death & $\checkmark$ & & & & $\checkmark$ & $\sqrt{ } \dagger$ & $\checkmark$ & $\sqrt{ } \ddagger$ \\
\hline Cause of death & & & & & $\sqrt{ } \S$ & $\sqrt{ } \dagger$ & $\checkmark$ & $\sqrt{ } \ddagger$ \\
\hline \multicolumn{9}{|c|}{$\begin{array}{l}\text { *Absence or presence of chemotherapy. } \\
\text { †lf death occurred in hospital. } \\
\text { †lf death occurred in emergency department. } \\
\text { §Cancer related or non-cancer related. } \\
\text { APDC, Admitted Patients Data Collection; CCR, Central Cancer Registry; EDDC, Emergency Department Data Collection; RBDM, Register } \\
\text { of Births, Deaths and Marriages; RPBS, Repatriation Pharmaceutical Benefits Scheme. }\end{array}$} \\
\hline
\end{tabular}

The original proposals were submitted in two phases, the first of which approved the linkage of the DVA client data with NSW CCR and the RPBS data (approval numbers: 2008/02/060 and, E008/003). The second phase approved the linkage of the remaining data sets (approval numbers: 2010/03/217 and E010/009). The two-phased approach was developed after discussions with the DVA and NSW Ministry of Health data custodians. Given the novelty of the linkage, it was determined that the first linkage should be used to demonstrate the feasibility of the linkage after which time the additional data would be linked. Despite this, there was a 3-year delay between the first ethics approval and delivery of the data. The primary impediments related to a lack of capacity within the various agencies to extract the data and due to challenges in negotiating and signing a data service agreement between the DVA (a Commonwealth agency) and an academic institution.

The data for the research programme were released without individual consent. Therefore, the ethical and privacy issues related to the use and disclosure of information for a secondary purpose, and waiving informed consent. The use and disclosure of Commonwealth and state data are governed under the Privacy Act 1988 and Health Records and Information Privacy (HRIP) Act 2003, respectively. Information Privacy Principle (IPP) 2 under the Privacy Act 1988 (Commonwealth) provides that personal information should not be used or disclosed for any purpose other than the primary purpose of the collection. Further, Health Privacy Principles 10 and 11 of the HRIP Act provide that an organisation can only use and disclose health information for the purpose for which it was collected, or a directly related purpose.

We sought approval to use of data for a secondary purpose, that of research involving data linkage.

- Under IPP2.1(d) use or disclosure for another purpose is permitted if (1) it is necessary for research and it is impracticable to gain consent and (2) the use is in accordance with the section 95A guidelines (which provides a process to resolve the conflict that may arise between the public interest in privacy and the public interest in medical research).

- The statutory guidelines under the HRIP Act define the scope of particular exemptions in the health privacy principles. Under this act, data can be disclosed for a secondary purpose, such as research using the 'research exemption'.

As such, we applied for these exemptions to the current research programme.

We sought to waive individual consent for the release of data because:

- It is not possible or practical to obtain consent because of the large study population (more than 100000 DVA clients) and a large proportion of DVA clients were likely to be deceased.

- Obtaining consent would prejudice the scientific value of the research due to the high participation rates required for unbiased samples (at least 90\%) and the Australian evidence about the sociodemographic differences between participants who consent to data linkage research and those that do not. ${ }^{57}$

- The public interest in the research outweighs the public interest in privacy protection. This is because we know little about the way in which medicines are used in the real-world marketplace. Our research has the potential to address key issues such as the risks and benefits of specific cancer medicines in a subgroup of Australians.

We minimised the risk to personal privacy by:

- A third party, the CHeReL, undertaking the record linkage, ensuring the smallest number of people have access to the identifiable data.

- Ensuring data are stored securely.

- Restricting access to identified data to officers in the CHeReL, whose access is password protected and subject to the signing of a confidentiality agreement. 
- Separating the data linkage process (where access to personally identified data is necessary), from the data analysis, so that personal information and health information are separated.

- Ensuring researchers will not be in possession of any personal identifying information. The identifiable information (such as name and address) will be removed from the content data by linkage staff after record linkage has taken place.

- Ensuring the files released to researchers will not contain DVA clients' actual enrolment number, rather a unique project number generated by CHeReL staff.

- Ensuring identifiable information will not be published.

\section{Dissemination plan}

The outcomes of this research will be submitted to international peer-reviewed journals; in particular oncology, general medical and pharmacoepidemiology journals. Furthermore, results will be presented at national and international oncology and pharmacoepidemiology conferences. We will also develop lay summaries of research findings for communication to consumer groups and policy makers where appropriate. As stipulated in our DVA data agreement we will submit all data that will be communicated in the public domain to the DVA for review and approval. Authorship will be based on the International Committee of Medical Journal Editors guidelines. Outcomes will also be posted on the University of Sydney webpage of the lead investigator and the Centre for Research Excellence in Medicines and Ageing website (under development). Direct access to the data and analytical files to other individuals or authorities is not permitted without the express permission of the approving human research ethics committees and data custodians.

\section{DISCUSSION}

The programme outlined in this protocol will form a solid foundation for cancer pharmacoepidemiology research and will allow Australian researchers to capitalise on the evidence derived and learning gained from this programme of work. Observational studies of the kind described in this protocol are particularly important as the elderly are under-represented in clinical trials but are the subpopulation with the highest rates of medicine use ${ }^{58}$ and are at the most at risk of adverse events. ${ }^{59} 60$ The DVA have a strong tradition of making data available for research purposes and this programme will establish a long-term programme in cancer pharmacoepidemiology.

Moreover, there have been encouraging developments in Australia in recent years that will increase the opportunities for Australian researchers to undertake whole of population, pharmacoepidemiology research. At the national level, the Department of Human Services (custodians of Medicare and PBS data) now provides timely access to person-level medicines dispensing data. At the state level, major linked data resources incorporating hospital separations, ED visits, cancer registrations, mental health service use and fact and cause of death data have been available for nearly two decades via the Western Australian Data Linkage System (WADLS) and the NSW CHeReL since 2006. A similar service has been recently established in South Australia and the Northern Territory via SA-NT Datalink. Other states will follow in the near future due to the injection of more than $\$$ A60 million by the National Collaborative Research Infrastructure Strategy (NCRIS). Moreover, there is a strong commitment from government for linked Commonwealth and State data through Integrating Authorities, which have become operational in 2012. With these advances cancer pharmacoepidemiology research in Australia has a bright future.

Acknowledgements The authors would like to thank the Australian Government Department of Veterans' Affairs (DVA) and the New South Wales (NSW) Ministry of Health for data provision and the Centre for Health Record Linkage for undertaking the data linkage process.

Contributors S-AP and AS drafted and approved the final manuscript. AS conducted the data analysis.

Funding This data linkage was funded by a Cancer Australia Project Grant (Number 568773). From 2014, the programme will be partly funded by the NHMRC Centre of Research Excellence in Medicines and Ageing (1060407).

Competing interests Sallie Pearson is a Cancer Institute NSW Career Development Fellow (12/CDF/2-25). Sallie Pearson was based at the University of NSW at the time she established the research programme. She is now at the University of Sydney.

Ethics approval The research programme was approved by the New South Wales Population and Health Services and DVA Human Research Ethics Committees

Provenance and peer review Not commissioned; externally peer reviewed.

Open Access This is an Open Access article distributed in accordance with the Creative Commons Attribution Non Commercial (CC BY-NC 3.0) license, which permits others to distribute, remix, adapt, build upon this work noncommercially, and license their derivative works on different terms, provided the original work is properly cited and the use is non-commercial. See: http:// creativecommons.org/licenses/by-nc/3.0/

\section{REFERENCES}

1. DeVita VT Jr, Rosenberg SA. Two hundred years of cancer research. N Engl J Med 2012;366:2207-14.

2. Baselga J, Carbonell X, Castaneda-Soto N, et al. Phase II study of efficacy, safety, and pharmacokinetics of trastuzumab monotherapy administered on a 3-weekly schedule. J Clin Oncol 2005;23:2162-71.

3. Rawlins MD. Cutting the cost of drug development? Nat Rev Drug Discov 2004;3:360-4.

4. Birkett D, Mitchell A, McManus P. A cost-effectiveness approach to drug subsidy and pricing in Australia. Health Aff 2001;20:104-14.

5. Kelman CW, Pearson SA, Day RO, et al. Evaluating medicines: let's use all the evidence. Med J Aust 2007;186:249-52.

6. Banks E, Pearson S. A life-cycle approach to monitoring benefits and harms of medicines: collection of high-quality data and management of risk are ongoing needs. Med J Aust 2012;197:2

7. Avorn J. In defense of pharmacoepidemiology-embracing the yin and yang of drug research. N Engl J Med 2007;357:2219-21.

8. Australian Government Department of Health and Ageing. National Medicines Policy 2000. Canberra: Commonwealth of Australia, 1999.

9. Mealing NM, Dobbins TA, Pearson SA. Validation and application of a death proxy in adult cancer patients. Pharmacoepidemiol Drug Saf 2012;21:742-8.

10. Pearson S-A, Ringland CL, Ward RL. Trastuzumab and metastatic breast cancer: trastuzumab use in Australia-monitoring the effect of 
an expensive medicine access program. J Clin Oncol

2007;25:3688-93.

11. Stavrou EP, Buckley N, Olivier J, et al. Discontinuation of statin therapy in older people: does a cancer diagnosis make a difference? An observational cohort study using data linkage. BMJ Open 2012;2: e000880.

12. Stavrou EP, Lu CY, Buckley N, et al. The role of comorbidities on the uptake of systemic treatment and 3-year survival in older cancer patients. Ann Oncol 2012;23:2422-8.

13. Damianovich D, Adena M, Tebbutt NC. Treatment of 5-fluorouracil refractory metastatic colorectal cancer: an Australian population-based analysis. Br J Cancer 2007;96:546-50.

14. Vitry AI, Thai LP, Lu CY. Time and geographical variations in utilization of endocrine therapy for breast cancer in Australia. Intern Med J 2011;41:162-6.

15. Wettermark B, Zoëga H, Furu K, Korhonen M, et al. The Nordic prescription databases as a resource for pharmacoepidemiological research - a literature review. Pharmacoepidemiol Drug Saf 2013;22:9.

16. Kalisch LM, Roughead EE, Gilbert AL. Pharmaceutical brand substitution in Australia-are there multiple switches per prescription? Aust N Z J Public Health 2007;31:348-52.

17. Kalisch LM, Roughead EE, Gilbert AL. Brand substitution or multiple switches per patient? An analysis of pharmaceutical brand substitution in Australia. Pharmacoepidemiol Drug Saf 2008;17:620-5.

18. Parkes AJ. Starting SSRI antidepressant therapy: its effect on tricyclic antidepressant and benzodiazepine prescribing. Med J Aust 1996; $164: 509$

19. Parkes AJ, Coper LC. Inappropriate use of medications in the veteran community: how much do doctors and pharmacists contribute? Aust N Z J Public Health 1997;21:469-76.

20. Pearson SA, Ringland C, Kelman C, et al. Patterns of analgesic and anti-inflammatory medicine use by Australian veterans. Intern Med $J$ 2007;37:798-805.

21. Ringland C, Mant A, McGettigan $P$, et al. Uncovering the potential risk of serotonin toxicity in Australian veterans using pharmaceutical claims data. Br J Clin Pharmacol 2008;66:682-8.

22. Roughead E, Pratt N, Peck R, et al. Improving medication safety: influence of a patient specific prescriber feedback program on rate of medication reviews performed by Australian general medical practitioners. Pharmacoepidemiol Drug Saf 2007;16:797-803.

23. Roughead EE, Anderson B, Gilbert AL. Potentially inappropriate prescribing among Australian veterans and war widows/widowers. Intern Med J 2007;37:402-5.

24. Roughead EE, McDermott B, Gilbert AL. Antidepressants: prevalence of duplicate therapy and avoidable drug interactions in Australian veterans. Aust N Z J Psychiatry 2007;41:366-70.

25. Roughead EE, Ramsay E, Pratt N, et al. NSAID use in individuals at risk of renal adverse events: an observational study to investigate trends in Australian veterans. Drug Saf 2008;31:997-1003.

26. Roughead EE, Ramsay E, Priess K, et al. Medication adherence, first episode duration, overall duration and time without therapy: the example of bisphosphonates. Pharmacoepidemiol Drug Saf 2009;18:69-75.

27. Roughead EE, Ramsay EN, Pratt NL, et al. Proton-pump inhibitors and the risk of antibiotic use and hospitalisation for pneumonia. Med J Aust 2009;190:114-16.

28. Australian Government Department of Veterans' Affairs (DVA) Veterans' Medicines Advice and Therapeutics Education Services. https://www.veteransmates.net.au/VeteransMATES/

VeteransMATESServlet?page=index

29. Australian Government Department of Veterans' Affairs. Eligibility \& claims factsheets. http://www.dva.gov.au/eligibilityandclaims/Pages/ Factsheets.aspx

30. Australian Government Department of Veterans' Affairs (DVA). DVAfunded health services: DVA eligibility requirements. http://www.dva gov.au/service_providers/services/Pages/health_services.aspx

31. Australian Government Department of Veterans' Affairs (DVA). Treatment population statistics: quarterly report-December 2010.

32. Australian Bureau of Statistics: 1217.0.55.001-Glossary of Statistical Geography Terminology, 2011. http://www.abs.gov.au/ ausstats/abs@.nsf/mf/1217.0.55.001\#PARALINK10

33. Australian Bureau of Statistics: 1216.0-Australian Standard Geographical Classification (ASGC). http://www.abs.gov.au/ausstats/ abs@.nsf/mf/1216.0
34. International Agency for Research on Cancer. Manual for Cancer Registry Personnel: IARC Technical Report No. 10 Vol. 1-4. Lyon, France: IARC, 1995:81.

35. Barraclough H, Morrell S, Arcorace M, et al. Degree-of-spread artefact in the New South Wales Central Cancer Registry. Aust N Z J Public Health 2008;32:414-16.

36. Centre for Health Record Data Linkage. Data dictionaries. http:// www.cherel.org.au/data-dictionaries\#section5

37. Jaro MA. Probabilistic linkage of large public health data files. Stat Med 1995;14:491-8.

38. Choice Maker. Open source record matching. http://oscmt. sourceforge.net/

39. (CHeReL) CfHRL. Quality assurance. http://www.cherel.org.au/ quality-assurance

40. Charlson ME, Pompei P, Ales KL, et al. A new method of classifying prognostic comorbidity in longitudinal studies: development and validation. J Chronic Dis 1987;40:373-83.

41. Sloan KL, Sales AE, Liu CF, et al. Construction and characteristics of the RxRisk-V: a VA-adapted pharmacy-based case-mix instrument. Med Care 2003;41:761-74.

42. Australian Bureau of Statistics. Remoteness structure. http://www. abs.gov.au/websitedbs/d3310114.nsf/home/remoteness+structure

43. Australian Bureau of Statistics. Socio-economic indexes for areas. http://www.abs.gov.au/websitedbs/censushome.nsf/ 4a256353001af3ed4b2562bb00121564/seifa

44. Charlson ME, Pompei P, Ales KL, MacKenzie CR. A new method of classifying prognostic comorbidity in longitudinal studies: development and validation. J Chronic Dis 1987;40: 373-83.

45. Elixhauser A, Steiner C, Harris DR, et al. Comorbidity measures for use with administrative data. Med Care 1998;36:8-27.

46. Schneeweiss S, Rassen JA, Glynn RJ, et al. High-dimensional propensity score adjustment in studies of treatment effects using health care claims data. Epidemiology 2009;20:512-22.

47. Sylvestre MP, Abrahamowicz M. Flexible modeling of the cumulative effects of time-dependent exposures on the hazard. Stat Med 2011;28:3437-53.

48. West SL, Savitz DA, Koch G, et al. Recall accuracy for prescription medications: self-report compared with database information. $A m$ Epidemiol 1995;142:1103-12.

49. West S, Strom B, Freundlich B, et al. Completeness of prescription recording in outpatient medical records from a health maintenance organization. J Clin Epidemiol 1994;47:165-71.

50. Australian Government Department of Veterans' Affairs (DVA). Annual report 2006-2007. Canberra: DVA, 2007.

51. Parkin DM, Whelan SL, Ferlay J, et al. Cancer incidence in five continents. Lyon, France: IARC Press, 2002

52. Schneeweiss S, Avorn J. A review of uses of health care utilization databases for epidemiologic research on therapeutics. J Clin Epidemiol 2005;58:323-37.

53. Quan H, Li B, Couris CM, et al. Updating and validating the Charlson comorbidity index and score for risk adjustment in hospital discharge abstracts using data from 6 countries. Am J Epidemiol 2011;173:676-82.

54. Johnson ML, El-Serag HB, Tran TT, et al. Adapting the Rx-Risk-V for mortality prediction in outpatient populations. Med Care 2006;44:793-7.

55. Australian Institute of Health and Welfare (AIHW). Health care usage and costs. A comparison of veterans and war widows and widowers with the rest of the community. In., vol. Cat. no. PHE 4. Canberra: AlHW, 2002.

56. Holman CD. The impracticable nature of consent for research use of linked administrative health records. Aust $N Z J$ Public Health 2001;25:421-2

57. Young AF, Dobson AJ, Byles JE. Health services research using linked records: who consents and what is the gain? Aust $N Z J$ Public Health 2001;25:417-20.

58. Hajjar ER, Cafiero AC, Hanlon JT. Polypharmacy in elderly patients. Am J Geriatr Pharmacother 2007;5:345-51.

59. Field TS, Mazor KM, Briesacher B, et al. Adverse drug events resulting from patient errors in older adults. J Am Geriatr Soc 2007;55:271-6.

60. Gurwitz JH, Field TS, Harrold LR, et al. Incidence and preventability of adverse drug events among older persons in the ambulatory setting. JAMA 2003;289:1107-16. 